\title{
A Japanese version of the Pearlin and Schooler's Sense of Mastery Scale
}

Taisuke Togari ${ }^{*}$ and Yuki Yonekura²

\begin{abstract}
The aims of this research were to develop a Japanese version of Pearlin and Schooler's Sense of Mastery Scale (SOMS) and evaluate its reliability and validity. This survey targeted 4,000 men and women aged 25-74 living in Japan as of January 1, 2014, categorized them according to the region and size of the city in which they lived, randomly extracted 200 municipalities, and randomly extracted individuals after categorizing for sex and age based on the resident registries of each municipality. 2,067 survey responses were collected (response rate 51.7\%). We used weighted 7-item (SOMS-7) and 5-item (SOMS-5) versions that excludes two reverse items (item6 and 7) from SOMS-7 of the SOMS. From the item analysis, the item-total correlation coefficients of the two reverse items (items 6 and 7) were .03 and .34 . The Cronbach's alpha coefficient was also .69 in SOM-7 and .77 in SOMS-5. The partial correlation coefficients between SOMS and the sense of coherence, mental health inventory, self-rated health, and life satisfaction were all significant $(p<0.001)$. The SOMS showed high construct validity. SOMS-5 has sufficient reliability.
\end{abstract}

Keywords: Sense of mastery, Reliability and validity, Scale development, Japanese

\section{Background}

The sense of mastery, which is conceptualized as a coping mechanism to reduce stress, was proposed by Pearlin and Schooler (Pearlin and Schooler 1978). According to Pearlin, mastery is a self-belief, a conviction that people are able to control the important circumstances currently impinging on their life (Pearlin 2010). That sense of mastery is a protective resource with a stress-moderating capacity that has been repeatedly tested since the Sense of Mastery Scale (SOMS) was developed by Pearlin et al. in the 1970s (Pearlin and Bierman 2013). The sense of mastery also tends to develop from a background of successful attainment of socially prized goals, and therefore is related to advantageous socio-economic status (Pearlin et al. 2007).

In Japan, self-control-concepts related to one's health have been proposed, with the most well-known being the locus of control (Wallston et al. 1976). However, the sense of mastery is little known in Japan. Locus of control has more limited focus on the control of conditions that

\footnotetext{
*Correspondence: ttogari@ouj.ac.jp

${ }^{1}$ Faculty of Liberal Arts, The Open University of Japan, Chiba, Japan Full list of author information is available at the end of the article
}

individuals regard as important determinants of their own personal lives (Pearlin and Pioli 2003). Conversely, the sense of mastery focuses on all environmental conditions (Pearlin and Pioli 2003).

Despite much research on the use of the SOMS in Europe and the United States, a Japanese version has not yet been developed. Therefore, the aim of this research was to develop a Japanese version of Pearlin's SOMS, and examine its reliability and validity.

\section{Methods}

Forward translation and back translation

In creating the Japanese version of the SOMS, we first obtained the necessary permission from Prof. Pearlin. Second, our colleagues conducted a forward translation. Third, a bilingual person performed a back translation. Finally, Pearlin checked the back-translated items, and the items were revised based on his comments.

\section{Sample}

This survey targeted 4,000 men and women aged 25-74 living in Japan as of January 1, 2014, categorized them according to the region and size of the city in which they lived, randomly extracted 200 municipalities, and randomly

\section{Springer}


extracted individuals after categorizing for sex and age based on the resident registries of each municipality. This method was thereby a stratified two-stage extraction method. During the period from February to March 2014, in which self-administered questionnaires were sent out, 2,067 responses were collected using a leaving method (response rate 51.7\%). Cases with inadequate answers about the SOMS were extracted. The final sample size was 954 male and 1,101 female respondents, with a mean age (SD) of 50.0 (14.2). This research was approved by the institutional review board of The Open University of Japan.

\section{Variables}

\section{Sense of mastery scale}

The SOMS version used was Pearlin and Schooler's 7 -item version. This version included statements such as "There is really no way I can solve some of the problems I have" and "Sometimes I feel that I'm pushed around in life", and used a 4-point Likert scale with possible responses of "strongly disagree", "somewhat disagree", "somewhat agree", and "strongly agree" (Pearlin and Schooler 1978).

\section{Sense of coherence}

The sense of coherence (SOC) refers to the sense of looking at or confronting one's life and environments with the ability to cope with stressors. A 13-item SOC Scale (SOC-13) was used. The reliability and validity of this scale has been demonstrated (Eriksson and Lindström 2005). The total score was tallied using a 7-point semantic differential to serve as the SOC score. Cronbach's alpha coefficient $=.84$

\section{Mental health inventory}

Mental health was measured using the Japanese version of the five-item Mental Health Inventory (MHI5) related to depression and anxiety from the Medical Outcome Study Short Form (Rumpf et al. 2001). The reliability and criterion-related validity of this scale were verified for the Japanese population aged 16 or older (Yamazaki et al. 2005).

\section{Self-rated health}

Self-rated health (SRH) was measured on a 5-point scale ranging from "poor" to "excellent" in response to questions such as, "How is your present health?" SRH has been shown to affect survival rates controlled for objective health status (Idler and Benyamini 1997).

\section{Life satisfaction}

Life satisfaction was measured with a 5-point scale with the responses, "unsatisfactory", "rather unsatisfactory", "neither unsatisfactory nor satisfactory", "rather satisfactory", and "satisfactory" in response to questions such as, "How is the entirety of your life?"

\section{Statistical methods}

Two versions of the SOMS have been used in previous research, a 7 -item version (SOMS-7) and a 5-item version (SOMS -5) that excludes two reverse items from SOMS7. In recent years, SOMS-5 has been used frequently because of its good reliability (Deeg and Huisman 2010). In this study, both versions were weighed. First, reliability analyses [Cronbach's Alpha coefficients (Alpha)] and item-total correlations were computed. Second, confirmatory factor analysis by structural equation modeling was performed to examine factor validity. Third, sex and age group differences were examined using Student's $t$ test and one-way ANOVA. Finally, partial correlation analysis, controlled for age and sex, was performed to examine the relationships between the SOMS and related factors including SOC, MHI5, SRH and life satisfaction, as the construct validity. All analyses were conducted using IBM SPSS Statistics 22.0.

\section{Results}

From the item analysis (Table 1), the item-total correlation coefficients of the two reverse items (items 6 and 7) were .03 and .34. The Cronbach's alpha coefficient was also .69 in SOM-7 and .77 in SOMS-5. Confirmatory factor analysis regarding one-factor model resulted in follow model fit indices; CFI $=.86$ and $\mathrm{RMSEA}=.115$ for SOMS-7, CFI $=.98$ and RMSEA $=.074$ for SOMS-5. Mean values (SD) were 19.1 (3.3) for SOMS-7 and 13.8 (2.9) for SOMS-5. There were no differences between sexes in either scale. However, a one-way ANOVA showed significant differences $(\mathrm{F}=3.63, \mathrm{p}<0.001$ in SOMS-7; F $=7.28, \mathrm{p}<0.001$ in SOMS-5). Results of multiple comparison tests are shown in the Table 1. Partial correlation coefficients between the SOMS and related variables are shown in the Table 1 . All coefficients were significant $(\mathrm{p}<0.001)$.

\section{Discussion}

In this research, the SOMS had high construct validity; namely, the correlation coefficients between the SOMS and SOC were high, indicating a certain level of concurrent validity. SOC as well as the sense of mastery had stress-moderating effects (Idler and Benyamini 1997). Moreover, SOMS-5 and SOMS-7 were associated with MHI-5, SRH, and life satisfaction as mental health outcomes. Because the sense of mastery is a mediator of stress (Deeg and Huisman 2010), these results indicate that the SOMS has construct validity.

However, the Cronbach's alpha coefficient for SOMS-7 had a moderately low value. In addition, model-fit 


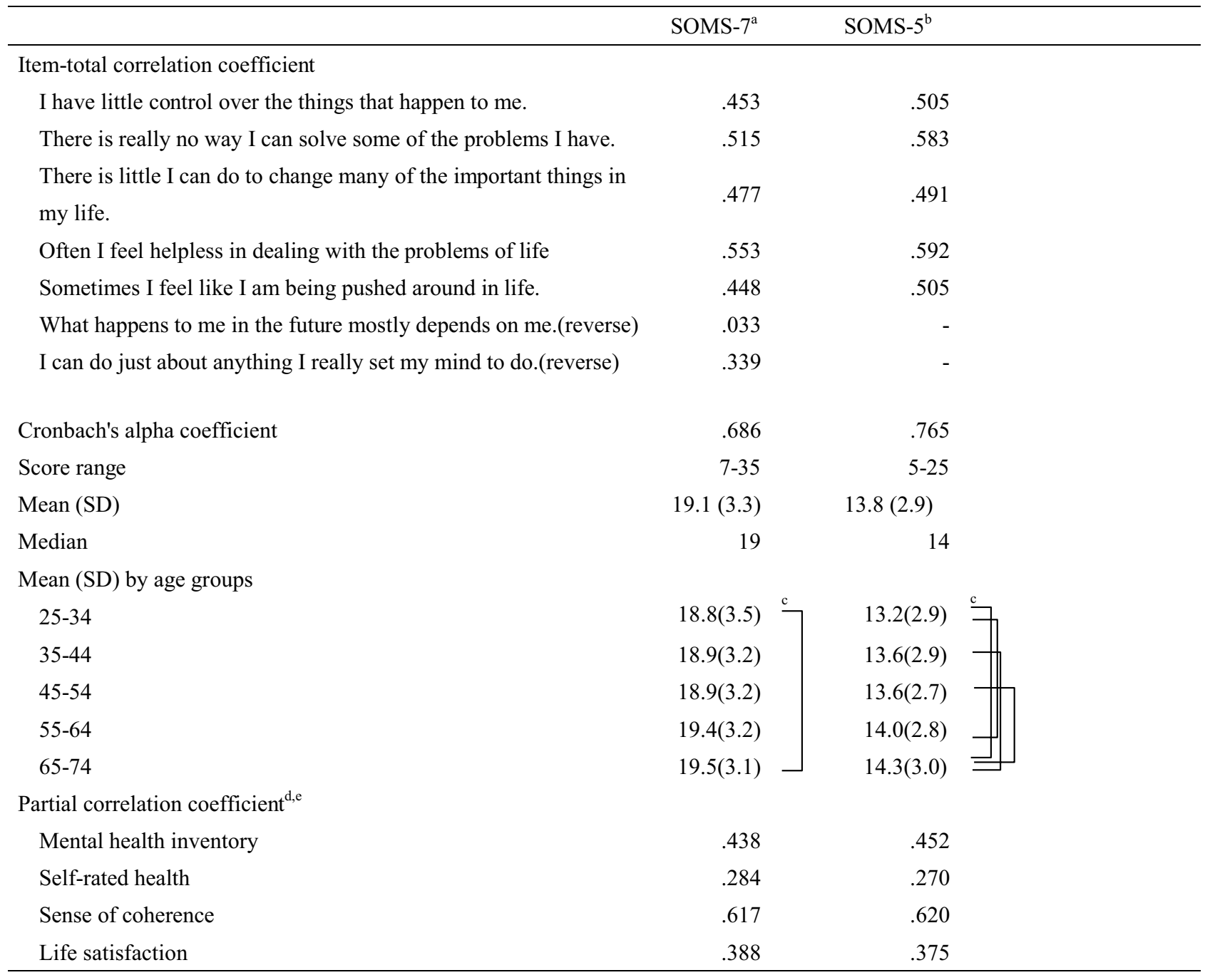

a 7-item version of sense of mastery scale.

b 5 -item version of sense of mastery scale.

c Tukey's multiple comparison test $(p<.05)$.

d Controlled for gender and age.

e All correlation coefficients were significant $(p<.001)$.

indicators for the confirmatory factor analysis were moderately low. Therefore, we need to treat findings regarding SOMS-7 with caution.

SOMS-5 does have sufficient reliability and factor validity. Because of its frequent usage in recent years, its Japanese version can be used without difficulty.

This study had some limitations. This study design was cross-sectional. In future research, we should conduct follow-up surveys and study predictive validity and test-retest reliability. As directions for future study, it is also important to study reproducibility, the predictability of health-related indicators from the perspective of construct validity, and the stress-buffering effects by way of longitudinal research.

\section{Authors' contributions}

TT drafted the manuscript. YY edited and revised the manuscript. Both authors read and approved the final manuscript.

\section{Author details}

${ }^{1}$ Faculty of Liberal Arts, The Open University of Japan, Chiba, Japan. ${ }^{2}$ Department of Hygiene and Preventive Medicine, Iwate Medical University, Morioka, Japan.

Acknowledgements

This work was supported by JSPS KAKENHI Grant Number 25285157. 


\section{Compliance with ethical guidelines}

\section{Competing interests}

The authors declare that they have no competing interests.

Received: 28 January 2015 Accepted: 27 July 2015

Published online: 07 August 2015

\section{References}

Deeg DJH, Huisman M (2010) Cohort differences in 3-year adaptation to health problems among Dutch middle-aged, 1992-1995 and 2002-2005. Eur J Ageing 7:157-165. doi:10.1007/s10433-010-0157-1

Eriksson M, Lindström B (2005) Validity of Antonovsky's sense of coherence scale: a systematic review. J Epidemiol Community Health 59:460-466. doi:10.1136/jech.2003.018085

Idler EL, Benyamini Y (1997) Self-Rated health and mortality: a review of twenty-seven community studies. J Health Soc Behav 38:21-37

Pearlin LI (2010) The life cource and the stress process: some conceptual comparisons. J Gerontol Ser B 65B:207-215. doi:10.1093/geronb/gbp106

Pearlin LI, Bierman A (2013) Current issues and future directions in research into the stress process. In: Aneshensel CS, Phelan JC, Bierman A (eds) Handbook of the sociology of mental health, 2nd edn. Springer, New York, pp 325-340
Pearlin LI, Pioli MF (2003) Personal control: some conceptual turf and future directions. In: Zarit SH, Pearlin LI, Schaie KW (eds) Personal control in social and life course context. Springer, New York, pp 1-21

Pearlin LI, Schooler C (1978) The structure of coping. J Health Soc Behav 19:2-21

Pearlin LI, Nguyen KB, Schieman S, Milkie MA (2007) The life-cource origins of mastery among older people. J Health Soc Behav 48:164-179. doi:10.1177/002214650704800205

Rumpf H, Meyer C, Hapke U, John U (2001) Screening for mental health: validity of the MHI-5 using DSM-IV Axis I psychiatric disorders as gold standard. Psychiatr Res 105:243-253. doi:10.1016/S0165-1781(01)00329-8

Wallston BS, Wallston KA, Kaplan GD, Maides SA (1976) The development and validation of the health related locus of control (HLC) scale. J Consult Clin Psychol 44:580-585. doi:10.1037//0022-006X.44.4.580

Yamazaki S, Fukuhara S, Green J (2005) Usefulness of five -item and threeitem Mental Health Inventories to screen for depressive symptoms in the general population of Japan. Health Qual Life Outcomes 3:48. doi:10.1186/1477-7525-3-48

\section{Submit your manuscript to a SpringerOpen ${ }^{\odot}$ journal and benefit from:}

- Convenient online submission

- Rigorous peer review

- Immediate publication on acceptance

- Open access: articles freely available online

- High visibility within the field

- Retaining the copyright to your article

Submit your next manuscript at $\boldsymbol{~ s p r i n g e r o p e n . c o m ~}$ 